Annual Courses

Title: Courses in Sexual and Reproductive Health organised by The Margaret Pyke Trust. Details: See display advertisement on the inside back cover.

Annual Courses

Title: Courses in Sexual and Reproductive Health organised by the University of Liverpool. Details: See display advertisement on the inside back cover.

\section{January 2008}

Title: The Beginning of the End for Cervical Cancer? Venue: The Main Lecture Theatre, Royal Society of Medicine, London, UK. Details: Carcinoma of the uterine cervix may not be the commonest cancer in women but the relatively young incidence and invasive potential of the tumour underline its importance. Previous strategies to contain and cure the disease have depended upon early diagnosis provided by cytological screening. Immunisation against human papillomavirus (HPV) now offers the prospect of neutralising the main causative factor. This conference will review current methods of detection before considering the likelihood of preventing HPV infection plus the psychological and logistic aspects of such a policy. Accreditation: 5 CPD. Information: Fenella Williams, Academic Department, Royal Society of Medicine, 1 Wimpole Street, London, W1G 0AE, UK. Tel +44 (0) 207290 2965. Fax: +44 (0) 20 7290 2989. E-mail: Fenella.williams@ rsm.ac.uk.

19 February 2008

Title: BASHH/FSRH Joint Meeting. Venue Royal Society of Medicine, London, UK. Details: See display advertisement on page 71.

\section{March 2008}

Title: 122nd Meeting of the Northern Interbranch Group. Venue: The Source, Sheffield, UK. Details: A 1-day update for members and guests on Sexual and Reproductive Healthcare. Topics to include: delaying first sex in young people, psychosexual therapy, GUM update and, back by popular demand, Professor James Trussell of Princeton University, USA speaking on "Much ado about little: obesity, combined hormonal contraceptives, and venous thrombosis". Accreditation: FSRH and PGEA applied for. Information: Dr Jenny Manuel, Chapeltown Health Centre, Spencer Place, Leeds LS7 4BB, UK. Tel: +44 (0) 1132407000. E-mail: jennifer.manuel@nhs.net.

\section{March 2008}

Title: North West Society of Sexual Medicine and Family Planning Spring Meeting Venue: The Birchwood Centre, Warrington, UK Details: Morning session: stress incontinence "Ooh doctor, I've got a discharge"; headache and contraception. Afternoon session: interactive session with panel on HIV. Accreditation: FSRH. Information: Mrs Linda Sloan, 5 Redhouse Lane, Eccleston, Chorley, Lancs PR7 5RH, UK. E-mail: lindasloan5@ btinternet.com.

\section{7-8 April 2008}

Title: Innovations and Progress in Healthcare for Women. Venue: The Queen Elizabeth II Conference Centre, London, UK. Details: A 2 day meeting for all healthcare professionals with an interest in women's health. Themes will include maternal and neonatal healthcare, reproductive health, and women's cancers. Accreditation: To be confirmed. Information: Meeting Organisers - IPHW 08, Confab Consulting Ltd, Trafalgar House, Grenville Place, London NW7 3SA, UK. Tel: +44 (0) 208906 7778. Fax: +44 (0) 208906 7790. E-mail: IPHW08@confab-consulting.co.uk. See also display advertisement on this page.

\section{5-16 April 2008}

Title: Basic Introduction to Practical Gynaecology and Early Pregnancy Ultrasound. Venue: University College London, London, UK. Details: See display advertisement on page 72 .

\section{April 2008}

Title: Conference on Women's Health. Venue: University of Warwick, Coventry, UK. Details: Series of interesting and informative update lectures by some eminent professors and consultants on topics to include: HRT - facts and fantasies; urogenital problems - young and old; managing osteoporosis; epidemiology rules the (air) waves; the latest on contraception; endometriosis management. Further information and online booking available on website. Accreditation: FSRH. Information: Barbara Halstead, Women's Health Concern, Whitehall House, 41 Whitehall, London SW1A 2BY, UK. Tel: +44 (0) 1628524009 (direct) or +44 (0) 207451 1377 (main office). Fax: +44 (0) 2079251505 E-mail: bhalstead@womens-health-concern.org. Website: www.womens-health-concern.org.

\section{1-23 April 2008}

Title: DFFP Course. Venue: London, UK. Details: A 3-day course suitable for doctors wishing to obtain the Diploma of the FSRH (of the RCOG). The course is also suitable for updating family planning doctors. Accreditation: FSRH applied for. Information: Grace Gray, Training Administrator, Sexual \& Reproductive Health Training Partnership, Southwark PCT, St Giles Road, London SE5 7RN, UK. Tel: +44 (0) 207771 3322. Fax: +44 (0) 2077713338 E-mail: srhtp@southwarkpct.nhs.uk.

30 April-3 May 2008

Title: 10th Congress of the European Society of Contraception: Non-contraceptive Impact of Contraception and Family Planning. Venue: Prague Congress Centre, Prague, Czech Republic. Details: Scientific programme of a high standard with plenary sessions, keynote lectures, congress sessions, fora, workshops, 'meet the expert' sessions, working group sessions, society sessions, symposia, FC sessions and young scientist session. Simultaneous translation into Russian and French. Accreditation: Continuing Medical Education (CME) credits. Information: ESC Central Office, Orga-Med Congress Office, Opalfeneweg 3 , 1740 Ternat, Belgium. Tel: +32 2582 0852. Fax: +32 2582 5515. E-mail: esccentraloffice@ contraception-esc.com.

\section{6-9 May 2008}

Title: The Mind/Hormone Interface in Community Gynaecology. Venue: Warwick Medical School, Coventry, UK. Details: See display advertisement on page 71 .

\section{2-23 May 2008}

Title: Faculty of Sexual and Reproductive Healthcare Annual Scientific Meeting 2008. Venue: Royal Armouries, Leeds, UK. Details: See display advertisement on page 71 .

There is a charge of $£ 55.00+$ VAT for each meeting/ course publicised in this section of the Journal. This will guarantee inclusion in the issue requested. For guaranteed inclusion in the April 2008 issue all course details should be with Sarah Monger by 15 February 2008. For a booking form please contact Sarah Monger at PMH Publications, PO Box 100 Chichester, West Sussex PO18 8HD, UK. Tel: +44 (0) 1243 816689. Fax: +44 (0) 1243 567456. E-mail: sarah.monger@keywayspublishing.com.

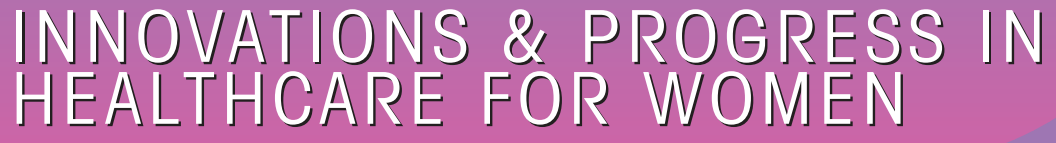

The Queen Elizabeth II Conference Centre, London, UK 7-8 April, 2008

Please register at the following website: www.womenshealth.uk.com Abstract submission is now open

University College WHS

London Hospitals 